\title{
Economic evaluation of 2014 cholera outbreak in Ghana: a household cost analysis
}

\author{
Dziedzom Kwesi Awalime ${ }^{1,2^{*}}$, Bernard Bright K. Davies-Teye², Linda A. Vanotoo², Nkechi S. Owoo \\ and Edward Nketiah-Amponsah"
}

\begin{abstract}
Introduction: Ghana experienced its worst cholera outbreak in three decades in 2014. Evidence of cholera economic costs on affected households has been limited. This study aimed at determining economic costs on households affected by the cholera outbreak in a Coastal Region of Ghana.

Methods: Two districts; High and Low Incidence Areas (HIA and LIA) were selected in comparative cost analysis and disease impact on affected households assessed based on scientifically documented economic indicators. A total of 418 (282 HIA and $136 \mathrm{LIA}$ ) households that experienced at least one case of cholera infection were interviewed. Direct and indirect costs were estimated. Correlates of household's cholera infection were estimated using Tobit Regression model in STATA 13.

Results: Average direct cost to households in HIA amounted to USD 106.88, almost 2 folds higher than LIA (USD 62.02). Potential cost saving of an episode of cholera is USD 99,201.28 in LIA and raises almost 8 folds in HIA (USD $782,611.60)$. Households in lowest income category had the highest incidence of cholera (0.073) compared to other categories plus other factors were significant in explaining cholera incidence.

Conclusions: The study showed considerable differences in HIA and LIA costs with higher household economic impact of cholera on the lowest income category. Results underscore the need for pragmatic policy interventions to avert recurrent outbreaks and emphasis huge potential cost saving with reducing cholera cases.
\end{abstract}

Keywords: Cholera, HIA, LIA, Cost of illness, Household, Ghana

\section{Background}

Economic measurements of disease complement clinical and epidemiological approaches in disease burden assessment. Economic analyses seek to address a number of policy questions on consequences of disease or injury [1]. Economic measurements ultimately translate into cost-savings with reduction of adverse health effects.

Health 'shocks' such as unexpected health expenditures, reduced functional capacity and lost income and productivity are primary risk factors for health impoverishment

\footnotetext{
* Correspondence: dawalime@gmail.com

${ }^{1}$ Economics Department, University of Ghana, Legon, P. O. Box LG 25, Accra, Ghana

${ }^{2}$ Ghana Health Service, Regional Health Directorate, P. O. Box 184, Accra, Greater Accra Region, Ghana
}

$[2,3]$. These factors pose a great burden on households which experience diseases such as cholera that presents symptoms only after patient is acutely ill.

"Cholera represents an estimated burden of 1.3 to 4.0 million cases, and 21,000 to 143,000 deaths per year worldwide" [4]. However, there could be as much as 100,000 to 120,000 cholera deaths every year but countries normally fail to report actual numbers due to fear of external economic implications on sectors like trade and tourism [4]. These numbers are corroborated by Ali et al. [5].

In parts of Ghana, cholera is now endemic and the country experiences outbreaks about every 5 years. In 2014, Ghana together with Nigeria and DR Congo reported 83\% of all cases in Sub-Saharan Africa [6]. In that 
same year, Ghana experienced its worst outbreak in three decades reporting 28,944 cases including 243 deaths coming only second to Nigeria in infection rates $[6,7]$.

Research on cholera in Ghana has focused more on epidemiology of outbreaks and little emphasis on economic costs. Studies which identify socio-economic factors [8-10] are not detailed but provide mostly socio-economic linkages.

This study estimated comparative cholera costs in high and low incidence areas (HIA \& LIA) plus correlates among cholera affected households. These provide empirical evidence to a lean literature on economic evaluations of cholera.

\section{Methods}

The study used Cost-of-Illness approach by Rice [11] including WHO guidelines [1] for estimating economic consequences of disease and injury. This guided the assessment of household costs. Data on direct and indirect cost implications were collected using structured questionnaires.

\section{Study sites}

The study was conducted in La-Dadekotopon and Shai-Osudoku districts within the Greater Accra Region. Historically, the region has become the epicenter for cholera outbreaks in the country. At the end of 2014, La-Dadekotopon and Shai-Osudoku documented 1907 and 315 cholera cases respectively. These districts ranked second and eighth respectively among the top ten districts that reported cases and where selected as high and low incidence districts respectively. Distinctive feature of these areas are that one is urban, highly polluted indigenes with mostly poor communities whilst the other is rural sparely populated mixed communities. These inherent differences help to understand the incidence and costs implications within these areas.

\section{Data and sampling}

Patient data was obtained from the Ghana Health Service line list for cholera outbreak. This contained names, place of residence, sex, age, laboratory test result, outcome of treatment and the telephone contact of patient. GHS used this database in contact tracing of cases and this same tool was used in tracing patients to their households. For the purposes of this study, population was defined as all positive cases of cholera reported from a particular district. These formed the basis of inclusion criteria with all other households excluded for no documented cases at the health facilities.

Random sampling procedure was adopted in selecting 418 households; 282 and 136 from a HIA and LIA respectively. More specifically, households were randomly selected from patient population database using a calculated sampling interval to help answer the research objectives of this study. Data collection was primary through interviews. Patients who were untraceable where replaced by new ones who were sampled through the same random selection process, traced and interviewed. There was over $90 \%$ response rate and those who refuse to grant interview were also replaced. All questionnaires were retrieved and data entered for analysis.

\section{Cost estimation \\ Direct costs}

Direct costs included; first aid, cost of transportation for patient and caregiver, consultation fees, drugs purchased, laboratory cost, facility admission cost (hoteling cost), under-the-table payments (unofficial payments), feeding costs (special diet and water) and burial costs (supervised burial) in the event of death. An accounting process was followed where all costs attributing to various components were summed to obtain the disease cost. Costs were separated based on low and high incidence area costs.

\section{Indirect costs}

The method adopted for measuring indirect cost (opportunity cost of ailment) was similar to that adopted by Sarker et al. [12]. This was done by computing the average household earnings as the base for determining the opportunity cost for the household. This average was then multiplied by the time component spent by the patient or caregiver for the time spent in travelling to and fro health facility, on admission and recovery after discharge. The time components include; travel time to facility, time spent at facility till discharge and work or school days lost after discharge. Waiting time with cholera treatment is reduced to zero because all cases brought into facilities are treated as emergencies and hence are not significant to this study. To ensure time loss estimates are not overweighed, during data collection only actively employed patients and caregivers were assumed to be losing productive hours and unemployed patients and caregivers time loss assumed to be zero.

\section{Cholera correlates}

The study further examined relationship between cholera affected households using Tobit Regression model by observing the relevance of income categories and other household characteristics in relation to the proportion of household infection. Household's characteristics were examined within this framework, 
testing which income groupings bore the greatest burden of the outbreak.

The empirical model is specified as:

$$
\begin{aligned}
i C=\beta_{0} & +\beta_{1} I N C+\beta_{2} S E X+\beta_{3} M S+\beta_{4} R H H \\
& +\beta_{5} A G E+\beta_{6} E D U+\beta_{7} H I+\beta_{8} D W S
\end{aligned}
$$

$i C=$ proportion of Household members Infected (number of infected persons divided by total household size).

$I N C=$ income category (categorical dummy; base: income above GH\$750; USD 234.38).

$S E X=$ sex (dummy variable; base: male).

$M S=$ marital status (dummy variable; base: married).

$R H H=$ relationship with household head (categorical dummy; base: Other dependents); head of household, spouse, daughter or son.

$A G=$ age (continuous variable).

$E D U$ = education (categorical dummy; base: highest education (above Secondary); none, basic, secondary/ technical/vocational.

$H I=$ health insurance status (dummy variable; base: not insured).

$D W S$ = drinking water source (categorical dummy; base: Inside Plumbing/Inside Standpipe); water vendor, neighbouring house, public standpipe and others.

\section{Results and discussion}

The total direct cost incurred by households in the HIA and LIA amounted to GH\$96,444.30 (USD 30,138.84) and GH\$26,991.30 (USD 8434.78) respectively (see Fig. 1 and Table 1). Treatment costs in both high and low incidence districts formed the highest cost driver for households. When admissions costs were added, facility costs formed over $70 \%$ of all direct costs. These costs have important implications for the health system because during the outbreak,

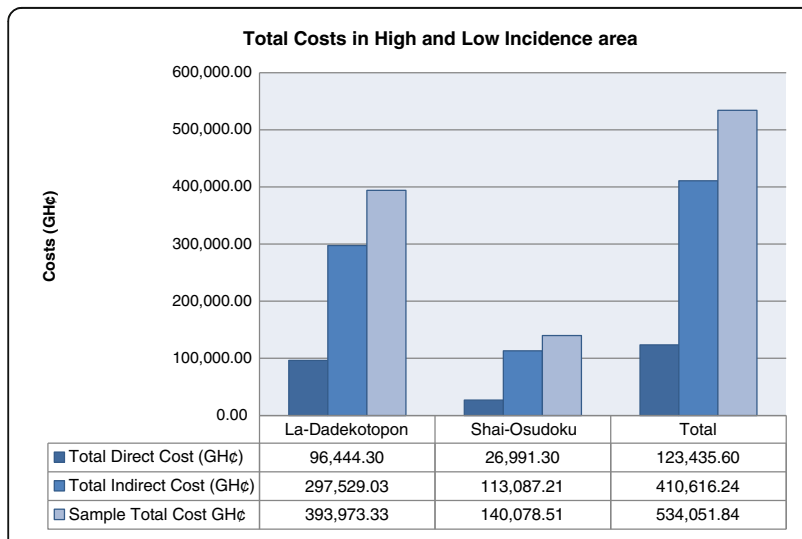

Fig. 1 Total Costs in High and Low cholera incidence areas cholera treatment was declared free but this outcome shows the contrary. In the HIA, direct cost composition showed treatment cost $(49.49 \%)$ as the largest component of the direct cost, followed by admission cost $(23.47 \%)$, transportation for both patient and caregiver (12.63\%), feeding $(12.09 \%)$ then first aid (2.32\%) (see Table 1).

From Table 2 on average it cost a household in a HIA GH\$342.00 (USD 106.88) and GH\$198.47 (USD 62.02) in a LIA to seek treatment. When compared to average costs reported by Sarker et al. [12] in Bangladesh (USD 30.40) average costs are two folds higher in the LIA and more than three folds higher in the HIA.

The average daily wage for households in the LIA was GH\$26.90, higher than in the HIA (GH\$22.80). On the other hand the average household size in LIA (3.6) is marginally smaller compared to HIA (3.7). These statistics have important bearings on the estimation of indirect costs within these two districts. Higher wages mean greater opportunity cost for lost man hours and household size influences the average household income; larger households mean lower per capita income and greater burden of the disease on that household.

In both districts, days missed by patients during recovery formed the largest composition of indirect costs but was $1 \%$ higher in HIA. Indirect costs associated with travel time were insignificant for both districts and is explained by existence of fairly easier access to transportation means in both districts (see Fig. 2). Average admission days was the same for both districts (3 days) but admission days formed a larger proportion of total indirect cost in the LIA (25\%) than the HIA (19\%) and in consonance, patients from LIA spent 2 days lesser away from normal daily activities than in the HIA (7 days). These suggest that complete recovery was faster and better in the LIA than the HIA.

From Table 3 an average of 25 days were missed in total by patients and caregivers away from their normal economic activities in the LIA but almost doubled in the HIA (48 days). This translated into GH\$1055.07 (USD 329.71) and GH\$831.52 (USD 259.85) average indirect cost for selected sample in the HIA and LIA respectively. Indirect costs in HIA were greater for all components than in LIA with the exception of productive days missed by caregivers. Total productivity loss by patients was GHc 141, 656.40 (USD 44,287.63) and GH \$ 52,858.50 (USD 16,518.28) in HIA and LIA respectively. That of caregivers was GH\$56,293.20 (USD 17,591.63) (HIA) and GH\$28,809.90 (USD 9003.09) (HIA). Together these costs formed over $70 \%$ of indirect cost composition. 
Table 1 Direct costs in high and low cholera incidence area

\begin{tabular}{|c|c|c|c|c|c|c|}
\hline \multirow[t]{2}{*}{ Direct Cost } & \multicolumn{2}{|c|}{ La-Dadekotopon } & \multicolumn{2}{|c|}{ Shai-Osudoku } & \multicolumn{2}{|l|}{ Total } \\
\hline & $\mathrm{GH} \zeta$ & USD\$ & $\mathrm{GHC}$ & USD\$ & $\overline{\mathrm{GH}}$ & USD\$ \\
\hline \multirow[t]{2}{*}{ First Aid } & 2236.60 & 698.94 & 283.80 & 88.69 & 3219.34 & 1006.04 \\
\hline & $(2.32)$ & & $(1.05)$ & & $(2.10)$ & \\
\hline \multirow[t]{2}{*}{ Treatment at Facility } & $47,729.00$ & $14,915.31$ & $12,885.00$ & 4026.56 & $75,529.31$ & $23,602.91$ \\
\hline & $(49.49)$ & & $(47.74)$ & & $(49.18)$ & \\
\hline \multirow[t]{2}{*}{ Feeding } & $11,658.00$ & 3643.13 & 3684.00 & 1151.25 & $18,985.13$ & 5932.85 \\
\hline & (12.09) & & $(13.65)$ & & $(12.36)$ & \\
\hline \multirow[t]{2}{*}{ Admission } & $22,637.00$ & 7074.06 & 6470.00 & 2021.88 & $36,181.06$ & $11,306.58$ \\
\hline & $(23.47)$ & & $(23.97)$ & & $(23.56)$ & \\
\hline \multirow[t]{2}{*}{ Transportation (Patient) } & 5912.00 & 1847.50 & 1410.00 & 440.63 & 9169.50 & 2865.47 \\
\hline & $(6.13)$ & & $(5.22)$ & & $(5.97)$ & \\
\hline \multirow[t]{2}{*}{ Transportation (Caregiver) } & 6271.70 & 1959.91 & 2258.50 & 705.78 & $10,490.11$ & 3278.16 \\
\hline & $(6.50)$ & & $(8.37)$ & & $(6.83)$ & \\
\hline Total & $96,444.30$ & $30,138.84$ & $26,991.30$ & 8434.78 & $123,435.60$ & $38,573.63$ \\
\hline
\end{tabular}

Bracket figures are percentages

Exchange rate: $1 \mathrm{USD}=\mathrm{GH} \zeta 3.20$ (Exchange rate as at December 31, 2014)

From Fig. 1 total cost to households were GHC 393,973.33 (USD 123,116.67) and GHष140,078.51 (USD 43,774.53) for sample selected in HIA and LIA districts respectively. In HIA indirect costs was markedly greater (above GH\$200,000 (USD 62,500) more) but in LIA just slightly above GH\$100,000 (USD 31,250).

In total, 2222 cholera cases were reported in health facilities; HIA (1907) and LIA (315). When costs are projected for the total number of cases reported for both districts, the total cost of the 2014 cholera outbreak in a high incidence situation is $\mathrm{GH}$ 2,504,357.12 (USD 782,611.60) and GH\$317,444.10 (USD 99,201.28) for lower incidence (see Fig. 3). Hence, if high incidence cases are reduced to levels of a lower incidence scenario, cost saving will be GH $\$ 2,186,913.02$ (USD 683,410.32).
Per capita costs within these areas amounts to GHC 1313.24 (USD 410.39) in the HIA and falls to GHC 1007.76 (USD 314.93) in the LIA (see Fig. 4).

The regression result from Table 4 supports the fact that the impact of cholera is felt largest by the lower income categories. Compared to the highest income bracket, households in the least income bracket are 7\% points more likely to experience a higher cholera incidence. For households within income brackets 3 and 4, there is a $6 \%$ points higher likely of infection compared with those in the highest income bracket. All are statistically significant at $10 \%$. These results corroborate the percentages in the cross-tabulation on the infection rates among these income categories. Both Borroto \& Martinez-Piedra [13] and Talavera \& Pérez [14] studies support impacts of cholera being heaviest on the least income people.

Table 2 Individual and household direct average costs

\begin{tabular}{|c|c|c|c|c|c|c|c|c|}
\hline & \multicolumn{4}{|c|}{ Individual Average Direct Cost } & \multicolumn{4}{|c|}{ HH Average Direct Cost } \\
\hline & \multicolumn{2}{|c|}{ La-Dadekotopon } & \multicolumn{2}{|c|}{ Shai-Osudoku } & \multicolumn{2}{|c|}{ La-Dadekotopon } & \multicolumn{2}{|c|}{ Shai-Osudoku } \\
\hline & $\mathrm{GHC}$ & USD & $\overline{\mathrm{GH}}$ & USD & $\overline{\mathrm{GH}}$ & USD & $\overline{\mathrm{GH}}$ & USD \\
\hline First Aid & 7.46 & 2.33 & 2.04 & 0.64 & 7.93 & 2.48 & 2.09 & 0.65 \\
\hline Treatment & 159.10 & 49.72 & 92.70 & 28.97 & 169.25 & 52.89 & 94.74 & 29.61 \\
\hline Feeding & 38.86 & 12.14 & 26.50 & 8.28 & 41.34 & 12.92 & 27.09 & 8.47 \\
\hline Admission & 75.46 & 23.58 & 46.55 & 14.55 & 80.27 & 25.09 & 47.57 & 14.87 \\
\hline Transportation (Patient) & 19.71 & 6.16 & 10.14 & 3.17 & 20.96 & 6.55 & 10.37 & 3.24 \\
\hline Transportation (Caregiver) & 20.91 & 6.53 & 16.25 & 5.08 & 22.24 & 6.95 & 16.61 & 5.19 \\
\hline Total & 321.48 & 100.46 & 194.18 & 60.68 & 342.00 & 106.88 & 198.47 & 62.02 \\
\hline
\end{tabular}

*Exchange rate: 1USD $=\mathrm{GH} \zeta 3.20$ (Exchange rate as at December 31, 2014)

Source: Survey Data; Author's computation from Excel 

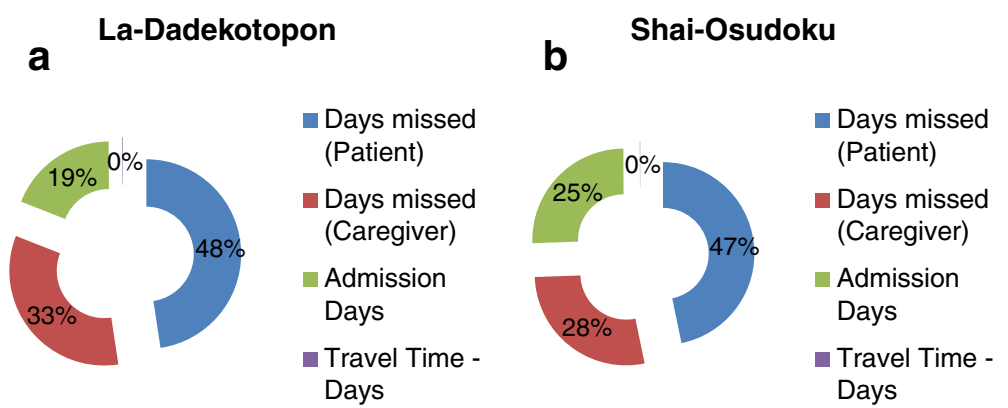

Fig. $\mathbf{2}$ a and $\mathbf{b}$ Indirect Cost Composition in high and low incidence areas

Households with unmarried persons have $14 \%$ likely incidence than their married counterparts. In 2013, an Oxfam research report on gender and vulnerability to cholera in Sierra Leone showed higher infection among unmarried males compared to married males [15].

Within the household composition, the impact of cholera was highest among dependents of household heads in the sample. There was $15 \%$ higher cholera incidence among this group in relation to the head of household. Spouses however had $4 \%$ less likely incidence of the disease.

Among adults is a higher tendency to eat away from home and mostly from unregulated commercial food vender around their places of work. The regression shows that with an additional year in age of a household member, there is $0.2 \%$ points higher likelihood of cholera infection at $1 \%$ significance level. However, Deen et al. [16] in a study of three cholera endemic areas (Jakarta, Kolkata and Biera) found that in all three areas, the impact of the disease was highest among children under five. There seems to be some contextual underpinnings accounting for these mixed results from these two different studies. This can however be understood through future investigation.

Within household composition, cholera impact was greatest among household heads' dependents. A 15\% higher proportion of cholera incidence was among this group in compared to household head. Spouses however had $4 \%$ less incidence of the disease during the outbreak.

The incidence of cholera and sources of water cannot be exaggerated and studies such as Crooks \& Hailegiorgis [17] support this fact. The safest source of drinking water as stipulated by the WHO is piped water on premises. Nketiah-Amponsah et al.'s [18] study's the socioeconomic determinants of drinking water source in Ghana and found that income increases access to piped water in residence by 29 percentage points. Asante [19] also found a significant statistical relationship between income and access to safe or portable water. Based on these, inside plumbing and inside standpipe was set as the reference

Table 3 Days missed by patients and caregivers with indirect costs in high and low incidence areas

\begin{tabular}{|c|c|c|c|c|c|c|}
\hline & & Days missed (Patient) & Days missed (Caregiver) & Admission Days & Travel Time (Days) & Total Missed Days \\
\hline \multirow[t]{2}{*}{ La-Dadekopon } & & 2071 & 1451 & 823 & 5 & 14,409 \\
\hline & Average & 6.90 & 4.84 & 2.74 & 0.02 & 48.03 \\
\hline \multirow[t]{4}{*}{ Shai-Osudoku } & & 655 & 388 & 357 & 1 & 6816 \\
\hline & Average & 4.71 & 1.41 & 2.57 & 0.00 & 24.79 \\
\hline & Total & 2726 & 1839 & 1180 & 6 & 5751 \\
\hline & & $\mathrm{GH} \zeta$ & $\mathrm{GH} \zeta$ & $\mathrm{GH} \zeta$ & $\mathrm{GH} \zeta$ & $\mathrm{GHC}$ \\
\hline La-Dadekopon & HH Total Indirect Cost & $141,656.40$ & $56,293.20$ & $99,248.40$ & 331.03 & $297,529.03$ \\
\hline Shai-Osudoku & HH Total Indirect Cost & $52,858.50$ & $28,809.90$ & $31,311.60$ & 107.21 & $113,087.21$ \\
\hline La-Dadekopon & $\mathrm{HH}$ Average Indirect Cost & 502.33 & 199.62 & 351.94 & 1.17 & 1055.07 \\
\hline \multirow[t]{2}{*}{ Shai-Osudoku } & $\mathrm{HH}$ Average Indirect Cost & 388.67 & 211.84 & 230.23 & 0.79 & 831.52 \\
\hline & Difference & 113.66 & -12.22 & 121.71 & 0.39 & 223.54 \\
\hline
\end{tabular}

Source: Survey Data; Author's computation from Excel 


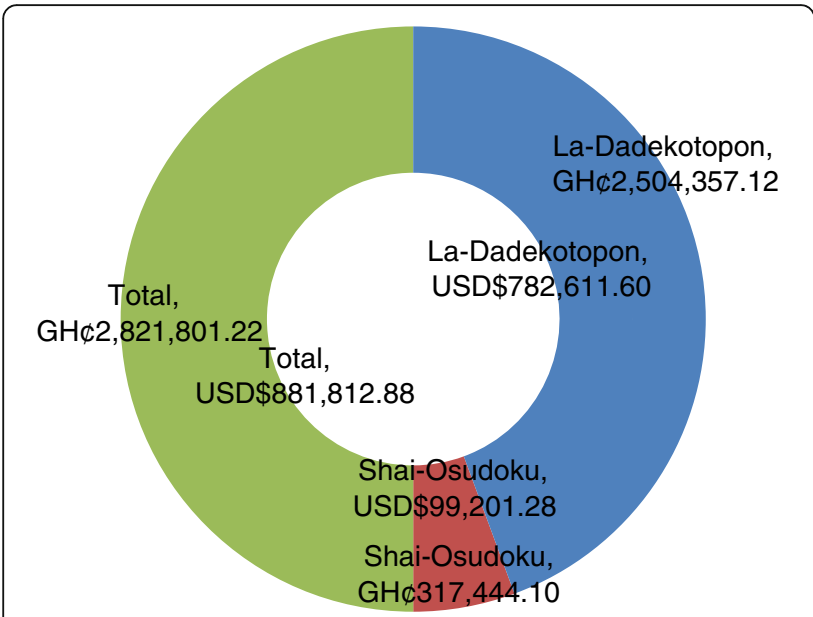

Fig. 3 Total Cost of 2014's Cholera Outbreak in High and Low Incidence Area

base for which other sources were compared. In the sample for this study, close to $70 \%$ of the households get their drinking water from a piped source, that is, an inside plumbing or in-house stand pipe (27.5\%), tab water in neighbouring house (18.1) or public stand pipe (42.0\%). These together formed $87.6 \%$ of drinking water sources that qualified as portable sources. The only water source that showed significance in relation to infection of cholera was water from neighbouring house. There was $5.8 \%$ higher cholera incidence in households that had their water sources from a neighbouring house as compared to household having inside plumbing as source of drinking water.

\section{Conclusion}

Facility costs incurred by households formed the highest cost drivers (forming over $70 \%$ of all direct costs in both HIA and LIA) regardless of the government intervention of free treatment of cholera. HIA showed four times higher direct cost to households (GH\$96,444.30; USD 30,138.84) compared to LIA (GH426,991.30 or USD 8434.78), representing four folds increased cost when incidence rises from low to high incidence scenario. Average costs in these scenarios saw a $25 \%$ increase of costs in HIA households mostly resulting from increased out-ofpocket payments due to medical supply shortages in health facilities within HIA. In both districts, indirect costs were important and higher than direct costs. It was over $50 \%$ higher for both districts $(51.0 \%$ and 61.4\% higher in HIA and LIA respectively). In HIA, patients spent an additional 7 days in recovery after discharge from hospital but reduced to 5 days in the LIA. Total cost saving in averting an episode of cholera amounts to GH\$2,504,357.12 (USD 782,611.60) in HIA but rises 8 folds in a LIA scenario GH4 317,444.10 (USD 99,201.28). Factors such as income quintile, marital status, age and some drinking water sources were significant correlates with the incidence of cholera.

One limitation of this study is its assumption of unemployed patients or caregivers having zero indirect costs, but since illness and caring for the sick can prevent job hunting or accepting offers of work this is a limitation.

Also, not all sampled cases could be traced and interviewed so had to be replaced. This formed about $10 \%$ of all selected cases.

\section{Significance for public health}

Cholera is a disease of poverty and continues to cause much strain on the resources of the health system as well as poor homes. The ease of spread and resulting costs cannot be downplayed. Cost analysis of cholera provides a key indicator of the

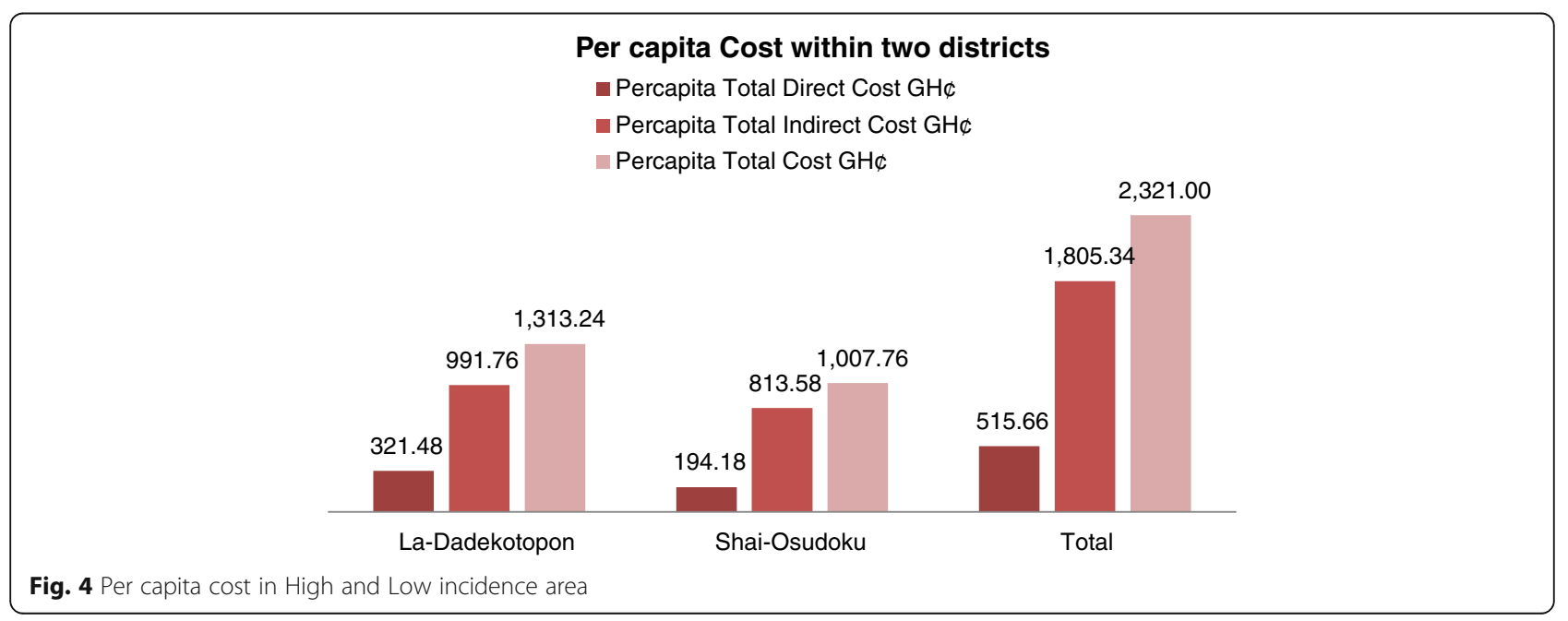


Table 4 Tobit regression output showing coefficients, marginal effects for censored sample, standard errors and $p$-values

\begin{tabular}{|c|c|c|c|c|c|c|}
\hline \multirow{2}{*}{$\overline{\text { Proportion of } \mathrm{HH}}$} & \multicolumn{3}{|c|}{ Tobit Regression } & \multicolumn{3}{|c|}{ Censored Sample } \\
\hline & Coef. & Std. Err. & $P>t$ & $d y / d x$ & Std. Err. & $P>z$ \\
\hline \multicolumn{7}{|c|}{ Income Grouping (Above GHC750) } \\
\hline C1: No Income & $0.073^{* *}$ & 0.032 & 0.022 & $0.019^{* *}$ & 0.009 & 0.036 \\
\hline C2: Less than GHC100 & 0.002 & 0.033 & 0.960 & 0.000 & 0.009 & 0.960 \\
\hline C3: > GHC100< <HC350 & $0.059^{* *}$ & 0.030 & 0.050 & $0.019^{* *}$ & 0.009 & 0.037 \\
\hline C4: > GHC350< <HÇ750 & $0.061^{* *}$ & 0.030 & 0.042 & $0.019^{* *}$ & 0.009 & 0.031 \\
\hline \multicolumn{7}{|l|}{ Sex (Male) } \\
\hline Female & 0.004 & 0.012 & 0.760 & 0.001 & 0.003 & 0.760 \\
\hline \multicolumn{7}{|l|}{ Marital Status (Married) } \\
\hline Not married & $0.137^{* * *}$ & 0.015 & 0.000 & $0.035^{* * *}$ & 0.004 & 0.000 \\
\hline \multicolumn{7}{|c|}{ Relationship with HH Head (Other Dependents) } \\
\hline Head of $\mathrm{HH}$ & 0.002 & 0.018 & 0.925 & 0.001 & 0.006 & 0.925 \\
\hline Spouse & $-0.043^{*}$ & 0.022 & 0.054 & $-0.015^{*}$ & 0.008 & 0.059 \\
\hline Son/Daughter & $0.146^{* * *}$ & 0.016 & 0.000 & $0.038^{* * *}$ & 0.004 & 0.000 \\
\hline Age & $0.002^{* * *}$ & 0.000 & 0.000 & $0.001^{* * *}$ & 0.000 & 0.000 \\
\hline \multicolumn{7}{|l|}{ Education (Higher) } \\
\hline None & 0.008 & 0.036 & 0.820 & 0.002 & 0.009 & 0.822 \\
\hline Basic & 0.017 & 0.034 & 0.619 & 0.005 & 0.009 & 0.610 \\
\hline $\mathrm{Sec} / \mathrm{Tec} N \mathrm{Noc}$ & 0.038 & 0.035 & 0.283 & 0.010 & 0.009 & 0.260 \\
\hline \multicolumn{7}{|l|}{ NHIS Enrolled (Yes) } \\
\hline No & -0.015 & 0.011 & 0.167 & -0.004 & 0.003 & 0.168 \\
\hline \multicolumn{7}{|c|}{ Drinking Water Source (Inside Plumbing/Standpipe) } \\
\hline Water vendor & 0.015 & 0.021 & 0.486 & 0.004 & 0.006 & 0.492 \\
\hline Neighbouring hse pipe & $0.058^{* * *}$ & 0.016 & 0.000 & $0.016^{* * *}$ & 0.005 & 0.000 \\
\hline Public Standpipe & 0.019 & 0.013 & 0.143 & 0.005 & 0.003 & 0.140 \\
\hline Other sources & 0.004 & 0.027 & 0.879 & 0.001 & 0.007 & 0.880 \\
\hline \multirow[t]{3}{*}{ Tobit regression } & & \multicolumn{5}{|c|}{ Number of obs $=1543$} \\
\hline & & \multicolumn{5}{|c|}{$\operatorname{LR} \operatorname{chi} 2(18)=315.16$} \\
\hline & & \multicolumn{5}{|c|}{ Prob $>$ chi $2=0.0000$} \\
\hline \multicolumn{2}{|l|}{ Log likelihood $=-3801.5065$} & \multicolumn{5}{|c|}{ Pseudo R2 $=0.0398$} \\
\hline
\end{tabular}

Significance levels $={ }^{* * *} p<0.01,{ }^{* *} p<0.05,{ }^{*} p<0.1$

financial strain on poor families when dealing with such menace.

- GHS must ensure the full and continuous implementation of its free cholera treatment.

- Need for social intervention policies such as free feeding or income compensations to mitigate impact.

- Importance of education on symptoms, first aid and need for early treatment by Information Services Department.

- Disparities of infection rates among different income groups plus other demographic variables highlights issues of discrimination and inequitable distribution of resources.

\section{Abbreviations}

DHRC: Dodowa Health Research Centre; GHS: Ghana Health Service; GSS: Ghana Statistical Service; HIA: High incidence area; ISSER: Institute of
Statistical Social and Economic Research; LIA: Low incidence area; WHO: World Health Organization

\section{Acknowledgements}

We are much grateful to Noguchi Memorial Institute for Medical Research for financial support through the Post-doctoral office that aided the facilitation this study. We also thank Ghana Health Service (GHS), Greater Accra Regional Health Directorate for providing initial household data and other useful resources for the study. As well as the LaDadekotopong and Shai-Osudoku District Hospitals and the Dodowa Health Research Institute (DHRI) for use of their facility.

\section{Funding}

A grant was won by the lead author from the Noguchi Memorial Institute for Medical Research, Legon Ghana. This grant was to aid data collection and was not conditioned to influence the design, collection of data, analysis, interpretation and writing of manuscript

This funding was provided under the Post-Doctoral Office of Sponsored Research which gives an annual grant to master students to support and aid quality research and mitigate financial constraints. 


\section{Availability of data and materials}

All datasets on which the conclusions of the manuscript rely are deposited in publicly available repositories and in the additional supporting files session of the submission.

\section{Sponsorship}

Noguchi Memorial Institute for Medical Research; Post-Doctoral Office.

\section{Publication of results}

The publication of study results was not contingent on the sponsor's approval or censorship of the manuscript.

\section{Authors' contributions}

Dziedzom Awalime identified the topic to research. Dziedzom Awalime, Nkechi Owoo and Edward Nketiah-Amponsah planned the study, executed the study and analyzed the data. Bright Davies-Teye \& Vanotoo critically reviewed the paper and provided certain sections of the data required. All authors wrote the paper.

\section{Ethics approval and consent to participate}

The Institutional Review Boards of the Institute of Statistical Social and Economic Research (ISSER); clearance number - ECH 033/14-15) and the Dodowa Health Research Centre (DHRC) clearance number - DHRC/IRB/15//03) reviewed and approved the study.

\section{Consent for publication}

The authors of this paper give consent for publication to the Health Economics Review.

\section{Competing interests}

All data collected for use in the study was proprietary work from authors. All models and methodology adopted from other sources are duly recognized and cited. The authors declare that they have no competing interests.

\section{Publisher's Note}

Springer Nature remains neutral with regard to jurisdictional claims in published maps and institutional affiliations.

Received: 14 March 2017 Accepted: 15 November 2017

Published online: 04 December 2017

\section{References}

1. World Health Organization. WHO guide to identifying the economic consequences of disease and injury; 2009.

2. World Health Organization. The world health report 1999: making a difference. Geneva: World Health Organization; 1999.

3. Xu K, Evans DB, Kawabata K, Zeramdini R, Klavus J, Murray CJ. Household catastrophic health expenditure: a multicountry analysis. Lancet. 2003;362(9378):111-7.

4. World Health Organization. Weekly Epidemiological Record. 2015. Available from: http://www.who.int/wer/2015/wer9040.pdf?ua=1. [Accessed 24 Nov 2016].

5. Ali M, Lopez AL, You Y, Kim YE, Sah B, Maskery B, Clemens J. The global burden of cholera. Bull World Health Organ. 2012;90(3):209-18.

6. World Health Organization. WHO Outbreak Bulletin. 2014;4(4). Available from: https://reliefweb.int/sites/reliefweb.int/files/resources/outbreak_ bulletin_issue_4_-september_2014.pdf. [Accessed 24 Nov 2016].

7. Ghana Health Service. Report on cholera outbreak in the Greater Accra Region: June to December, 2014. Accra: Ghana Health Service; 2015.

8. Dotse E, Odoom JK, Opare JK, Davies-Teye BBK. Outbreak of cholera, Greater Accra region Ghana 2014. J Sci Res Rep. 2016;9:3.

9. Davies-Teye BB, Vanotoo L, Yabani JB, Kwaakye-Maclean C. Socio-economic factors associated with cholera outbreak in Southern Ghana, 2012: a casecontrol study. Int J Epidemiol. 2015;44(suppl 1):i188.

10. De Magny GC, Cazelles B, Guégan JF. Cholera threat to humans in Ghana is influenced by both global and regional climatic variability. EcoHealth. 2006:3(4):223-31.

11. Rice DP. Estimating the cost of illness (health economics series no. 6, PHS no. 947-6). Washington, DC: US Government Printing Office; 1966.

12. Sarker AR, Islam Z, Khan IA, Saha A, Chowdhury F, Khan Al, Qadri F, Khan JAM. Cost of illness for cholera in a high risk urban area in Bangladesh: an analysis from household perspective. Infect Dis. 2013;13:518.
13. Borroto RJ, Martinez-Piedra R. Geographical patterns of cholera in Mexico, 1991-1996. Int J Epidemiol. 2000;29(4):764-72.

14. Talavera A, Perez EM. Is cholera disease associated with poverty? J Infect Dev Ctries. 2009:3(06):408-11.

15. Rancourt N. Gender and Vulnerability to Cholera in Sierra Leone: Gender analysis of the 2012 cholera outbreak and an assessment of Oxfam's response. 2013.

16. Deen JL, Von Seidlein L, Sur D, Agtini M, Lucas ME, Lopez AL, Kim DR, Ali M, Clemens JD. The high burden of cholera in children: comparison of incidence from endemic areas in Asia and Africa. PLoS Negl Trop Dis. 2008;2(2):e173.

17. Crooks AT, Hailegiorgis AB. An agent-based modeling approach applied to the spread of cholera. Environ Model Softw. 2014;62:164-77.

18. Nketiah-Amponsah E, Aidam PW, Senadza B. Socio-economic determinants of sources of drinking water: some insight from Ghana. Conference on International Research on Food Security, Natural Resource Management and Rural Development, University of Hamburg; 2009.

19. Asante FA. Economic analysis of decentralisation in rural Ghana. Peter Lang; Frankfurt am Main. 2003.

\section{Submit your manuscript to a SpringerOpen ${ }^{\circ}$ journal and benefit from:}

- Convenient online submission

- Rigorous peer review

- Open access: articles freely available online

- High visibility within the field

- Retaining the copyright to your article

Submit your next manuscript at springeropen.com 